\title{
Neonatal Pneumothorax, AE
}

National Cancer Institute

\section{Source}

National Cancer Institute. Neonatal Pneumothorax, AE. NCI Thesaurus. Code C154920.

An adverse event in a newborn characterized by a collection of air or other gas between the visceral and parietal pleura. 